\title{
Discourses in Interaction: The intersection of literacy and health research internationally
}

\author{
JULIE GREEN, JOSEPH LO BIANCO AND JOHANNA WYN
}

\begin{abstract}
Literacy and health are deeply influential in social participation, utilisation of social resources and quality of life. This paper discusses interacting discourses and common conceptual points shared by the adult literacy and public health fields and situates how the sub-field at the intersection of these two domains, known as 'health literacy', is constructed and enacted. Emerging approaches that recognise the convergence of education and health within international policy, research and in practice are articulated. The paper argues a case for re-thinking the literacy-health connection from a cross-sectoral perspective and for more effective approaches furthering the interests of both life-long learning and wellbeing.
\end{abstract}

\section{Introduction}

Scholarship in recent years has exposed both the autonomy of conceptualisation and the parallel developments that have characterised recent thinking in the literacy and health fields. Both have been subjected to dynamic scrutiny in which tenets of thinking previously held to be immutable have been challenged as new domains of application in people's lives have opened richer and more complex understanding of the literacy and health constructs that influence multiple aspects of people's lives. In academic writing, 'literacy' is seen to be a social practice, inflected in specific settings to meet the meaning-making needs of diverse individuals and groups, and fundamental to effective participation and contribution to a changing society (Lo Bianco and Freebody 2001, Snyder, Jones and Lo Bianco 2005). Similarly, 'health' is conceptualised as a positive concept, a resource needed to lead a productive life at individual, social and economical levels (Nutbeam 1999). Contemporary understandings of these fields emphasise the deeply influential effects of literacy and health in the extent of social participation they afford, the extent of utilisation of social resources they make possible and the quality of life that individuals and groups can attain.

These new and more extensive understandings of both constructs differ markedly from standard notions of health and literacy as tied irrevocably to institutions of formal education. Literacy is now seen as a socially situated practice and even the institutions of its formal delivery, assessment and cultivation, schools particularly, are analysed in relation to 
the chain of literacies of which formal education is only one link. Similarly for health, the role and relation of formal education in relation to health is no longer regarded as the key resource that determines good health (World Health Organisation 1986, Turrell, Stanley, de Looper and Oldenburg 2006), with a positive correlation between high levels of literacy and good health wellbeing (Parsons and Byner 1998, Institute of Medecine 2004). Today the connections between literacy and health are becoming more elaborated and better understood as research progressively uncovers the mutually interacting relation between health and active literacy.

This paper discusses common discourses and conceptual points shared by the adult literacy and public health fields, and issues arising from the mismatch between institutional and population literacies. The paper also considers the absence of innovative policy in the overall landscape of public action at the intersection of the literacy and health fields, and argues a case for re-thinking the literacy-health connection from a cross-sectoral perspective. Part of a wider project of re-thinking the paradigm of healthand-literacy, the aim is to pursue a line of questioning about the possible implications of a more coherent connection between health and literacy, and ultimately for more effective practices furthering the interests of both life-long learning and wellbeing.

\section{Linking literacy and health}

Poor literacy is likely to have detrimental consequences for people's health, usually within a context of social disadvantage or poverty, compromising the broader potential to take up practices to keep healthy (US Department of Health 2001, Nutbeam 2000). Low literacy is associated with difficulty in engaging in preventive health care practices when compared to people with more advanced literacy skills (Rudd, Moeykens and Colter 1999), in detecting disease early (Davis, Crouch, Wills, and Miller 1991, Lindau, Tomori, Lyons, Langseth, Bennett and Garcia 2002) and in accessing primary health care such as visiting a doctor (Rudd et al, 1999). There is a greater likelihood of missing important information on how to use valuable community-based resources (Dreger and Tremback 2002) and how to manage many aspects related to living with chronic illness (Silverstein, Iverson L and Lozano 2002, Williams, Baker, Honig, Lee, Nowlan 1998, Baker, Parker, Williams, Pitkin, Parikh, Coates and Imara 1996) and, because of the association between socio-economic disadvantage, relatively unskilled jobs and low literacy, people with low literacy are at a higher risk of disease, injury and death (Australian Institute of Health and Welfare (AIHW) 2004).

However, there is a wider, and shared, similarity between health and literacy constructs. Both function as an index of the success of societies in general, and measures of literacy and health stand indexically for social, 
political and civic accomplishments. One of the first indicators mentioned about a society will be a health or literacy score, seen to rise above contextual specificity and rank unproblematically as a cross-cultural marker. Health, particularly, functions as a kind of core signature theme of modern societies in general and is perceived to be a measure of the degree to which a society delivers a good life to its citizens (Marmot 2004). The capacity of health systems to promote health, however, relies to a considerable extent on people having good to high levels of literacy.

In post-industrial societies, taking personal responsibility for one's health and wellbeing has also become a core practice, where selfmanagement is referred to as 'individualisation' (Beck and Beck-Gernsheim 2002). These authors argue that as traditional systems and structures become fragmented and less effective, individuals are forced to take responsibility for managing their own biographies. A key element in this is the acceptance that health and wellbeing are the responsibility of individuals. Having the capacity to manage health and wellbeing, and demonstrating that self-efficacy and capacity, have become central components of citizenship in post-industrial societies. This means that individuals need to be reflexively literate in order to 'read' health messages, to make choices about the usefulness of these messages for their own lives and to act on them. The stress on individuals acting relatively autonomously in personal health management is an analogue of the practice of individuation that characterises official interpretations of literacy, and which distinguishes these from much of academic research and writing in literacy that typically embeds literacy within social situations as practices of collectivity. Both literacy and health, therefore, are part of social discourses in which different interests stress either a social or skills based selfmanagement on the one hand, or socially contextualised and embedded practices of culture and interpersonal relations on the other.

Both fields oscillate in how they are represented according to diverse interests and their conceptualisations of health and literacy. Both have been deeply impacted by systemic social change, including migration and the emergence everywhere of multicultural and therefore multilingual populations. At the same time, many previously stable social institutions, including family and ordered relations among ages, gender groups, and other identities, have been challenged, some dissolving, others resisting, the fragmentation pressures of contemporary post-industrial life. As modernist and individualist understandings of society itself fragment (provoking responses of defence and protection), personal management is substituted in place of predictability of systemic provision. The more personally selfmanaging mode of being in the social world, which might be called 'autonomist', in which people call on others to 'take charge' or to 'be responsible', is aligned with a new way of thinking about citizenship, best 
known as 'substantive' citizenship. This mode of being is at one with the contemporary spirit of the times, stressing individualism, autonomous operation in the world and involving declining levels of institutional responsibility.In this context, recognition of the impact of adult literacy on public health is growing within both the literacy and health fields.

\section{Positioning public health}

Within the broad health field, the notion of 'public health' is distinguished from the remediation of illness and focuses on the prevention of illness of populations through organised efforts of society (WHO 1998). Public health involves addressing social, environmental and cultural factors that support healthy living and positive environments and seeks to influence the factors which condition health outcomes, or which put people's good health at risk. As a result, public health substitutes the social for the individual and the proactive for the reactive.

Within this broad realm of public health, one of the cornerstones is heath promotion, a 'process of enabling people to increase control over, and to improve, their health' (WHO 1986:1), where health is conceptualised as a resource for living. This all-embracing understanding of the context of health and wellbeing disposes health promotion towards public policy and specifically towards policies that foster supportive environments for health in community and organisational settings as well as well as developing personal skills for individuals (Nutbeam and Harris 1998). Health promotion, then, is characterised by the creation of the essential conditions that enable communities to achieve their full health potential.

The campaign is an established form of health promotion. Examples include public education campaigns promoting safe sexual practices or physical activity; anti-smoking campaigns; ways to prevent skin cancer; and cautions about the effects of drinking and driving. However campaigns around single issue health concerns are only the most visible sign of a wider educative process that has traditionally been a vehicle of health promotion activity. Health education methods, involving an information, education and communication approach to targeted population groups, or to the entire community, aim, to improve knowledge, encourage the development of personal skills and influence choices and behaviour within people's everyday lives (Nutbeam 2005). Some public health education activities are seasonal, others are population specific, some are age, generation or gender targeted, while others again encompass the entire population. A recurring element is the aim to close gaps in disparities in health status and address factors that determine 'risk' across social groups.

Almost inevitably health promotion activity, evident in all of the examples cited, raises questions of personal and group identity and responsibility. Health promotion interacts, therefore, with the social 
practices of the community: how practices are judged according to immediate, as well as researched longer-term health effects; how social groups interact with other social groups; and the standing of individuals within the particular social groups to which they belong. As we can see, identity consequences inhere in both the behaviours of individuals and of relations among social groups. 'Risk' categories are, of course, an outsider definition structured around specialist health knowledge, and when minimisation of the risk to particular groups shapes public health promotions, obligations of dutiful citizenship are invoked and issues of differential literacy are raised. Individuals who fail to make the right 'choices', or those who make the right choices but are unable to sustain or implement them, not only fail to improve their health but risk becoming undeserving of citizenship. In these contexts 'literacy' is seen as an individual capability that either enhances or impedes the absorption by individuals of messages aimed at producing healthier living.

There is a growing level of attention to adult literacy within health promotion thinking, and of health questions within adult literacy research. The most obvious indicators of this are initiatives connecting adult literacy and public health, in policy, advocacy and practice as well as in academic settings, which we subsequently discuss.

Literacy has come to be considered central to the effective delivery of health promotion activity, and more widely to the empowerment of people and communities in self-managing health practices (Kickbusch 2001, Rootman and Ronson 2005, Rudd, Kirsh and Yamamoto 2004). While literacy is sometimes, and increasingly, considered as part of the infrastructure used to promote health (Hohn 1998, Nutbeam 2005), it is fair to say that the role accorded to literacy and communication practices, together with the conceptualisation of the communicative diversity of our society, is relatively understudied, and narrowly understood in many public health contexts. Perhaps the best way to formulate this is to note that the bulk of knowledge about health is coded, produced and disseminated in technical literate prose. It is expressed in standard English and embellished with statistical and graphic representations of probabilities, relations and effects between life styles, behaviours and predicted health consequences. Such literacy implies individual consumers of literate messages and involves a prestigious selection from the vast array of the literate practices of the wider society, with its various levels of literacy skill, multilingualism, and social practices in which texts are negotiated via cultural contexts that might include spoken communication, diverse kinds of authority and belief systems and histories of relations or rules of engagement between institutions and clients.

Issues of culture, identity, convergence of expectations, social complexity and empowerment feature increasingly in policy debates and 
research that will shape health promotion work in the future (IOM 2004). Whilst commonly informed by health and social research, health messages are seldom informed by current educational research or understandings of literacies and their impact on diverse populations. Even less consideration at the practice level is given to the productive use of the literacies and literacy practices of minority communities in increasing their engagement with health promotion messages and practices.

A logical step, therefore, is to look to the field of literacy to explore what constitutes literacy in a broader sense, accounting for the ways in which populations live their daily lives and how this may benefit the practice of public health and influence the promotion of health.

\section{Literacy discourses}

There is a significant disjunction between researchers' accounts of literacy as variable and socially situated (Heath 1983, Baynham 1995, Prinsloo and Breir 1996, Barton and Hamilton 1998, Barton, Hamilton and Ivanič 2000) and more general accounts that stress an unvarying, skillsbased and endlessly portable notion of literacy. Research accounts of literacy produced from richly contextualised ethnographic studies in many parts of the world, typical of what have been called New Literacy Studies (Street 2001, Street 2003, Baynham 2003), have little traction in much contemporary public policy or popular use.

Street (1995) has offered the terms 'ideological' and 'autonomous' to distinguish between these two perspectives in terms of origins. They can also be differentiated in terms of their purposes and intended effects. New Literacy Studies has aimed to explain the real world presence of literate behaviour, while policymakers and bureaucrats managing education systems have been addressing the management, accountability and resource distribution operations of public programs.

The distinction has direct bearing on our purposes in this paper, since the core aims of health promotion should make it sensitive to how individuals and various social groups relate to institutions in which communication activity, especially literacy, constitutes the dominant mode of interaction. Some researchers find that the way literate behaviour operates requires us to understand literacy as a cultural practice (Kalman 1999, Collins 1999), relevant in discussing cultural barriers to knowledge, information, skills and behaviours. Others have emphasised accessing that language and literacy are always embedded in other meaning-making practices and prefer the term 'multi-literacies' to describe how people ordinarily engage with the coding and de-coding of information in diverse but often integrated semiotic systems (Cope and Kalantzis 2000). Such writers frequently argue for policy and teaching to reduce barriers between 
formal and institutionalised literacy practices of education and those typically found in 'ordinary life' (Hamilton 2001).

Literacy overall has been the subject of debate and development, resulting in multiple, often contested, definitions. Ethnographic accounts of literacy invariably stress how literacy is a practice embedded in social activity, one of whose main consequences is to stress that everyday communication contexts of class, ethnicity, gender and generation (Freebody and Frieberg 1997) shape not only how literacy actually operates but how information and social behaviours are fashioned. We can see this sense of situatedness reflected in contemporary definitions of literacy as 'a complex set of abilities to understand and use the dominant symbol systems of a culture for personal and community development' (Centre for Literacy Quebec 2000).

Although the disparity between researcher and popular-official accounts of literacy is real, there is also evidence that ethnographies of literacy are shaping some official understandings as well. This is increasingly evident from the work of the Organisation for Economic Cooperation and Development (OECD). In its advocacy of 'life-long learning', the OECD (1996) estimates that only one-third of all adults in the majority of 'OECD countries' have achieved 'minimum' rates of literacy and numeracy. They connect this generalisation with trends about social activity, and economic production, towards greater knowledge intensiveness and towards deepening general links between economies and education, and more widely diffused information and communications technologies. From these connections emerge notions of the 'learning society' (OECD 1996:37), a basic tenet of life-long learning.

Although falling short of characterising literacy as a socially situated practice with personal and cultural meanings, the OECD nevertheless stretches the classical restricted notion of literacy as simply a psychological and motor skill, in saying that 'The very notion of literacy has evolved; in addition to reading, writing and numeracy skills, people also require technological and computer literacy, environmental literacy and social competence' (OECD 1996:39). For the OECD, signs of articulation among, or blurring of distinctions between, formal education and training, and learning in non-formal settings, and the related contraction of age boundaries between secondary and higher education, motivate what is ultimately a strong tie between 'culture' and literacy, viz, 'Raising a country's literacy profile requires a change in its culture' (OECD 1997:85).

Australian adult literacy research and practice has both shaped and been influenced by these wider international perspectives and has long been attuned to ideological as well as practical parameters of action as it identifies the influences of contexts, new settings and technologies (Wickert 2001, Snyder, Jones and Lo Bianco 2005). 
Australian practice has long rejected the dichotomisation of individuals or populations into categories of 'literate' and 'illiterate', proposing instead the more accurate depiction of a continuum of literacy in which individuals have variable capabilities (Wickert 2001). This better accounts for a range of skills activated in a variety of situations as well as the practical effects of this variation: 'the fact that what ultimately matters is the ability to grasp the meaning(s) ... and develop critical judgement' (United Nations Educational, Scientific and Cultural Organistation (UNESCO) 2005:127). In this context the link with health promotion is apparent. Originally perhaps focused overly on the idea of low literacy attracting social stigma, and negative effects of stigma in turn impacting on the possibility of achieving health promotion values (Rootman and Ronson 2005) what is emerging now is a more productive intersection labelled 'health literacy'.

\section{Understanding health literacy}

The term 'health literacy' has emerged in recent years to account for the intersection of interests and activities around the fields of both literacy and health (Freebody and Freiberg 1999, Nutbeam 2000, Freiberg Nutbeam and Kickbusch 2000). A number of definitions of health literacy have been offered from each of the health and the adult literacy sectors. These share a central concern with locating, understanding and using information for making health-related decisions and generating information for the promotion of health (WHO 1998, Ratzan and Parker 2000, IOM 2004).

Health literacy was stimulated initially by awareness among public health officials of correlations between low levels of income, education and poor health (Pamuk, Makuc, Heck, Reuben and Lochner 1998 cited in Rudd et al 1999, Baker, Parker, Williams and Clark 1998, Gazmararian, Baker, Williams, Parker, Scott, Green, Fehrenback, Ren and Koplan 1999) and by a long-standing practice of adult literacy educators of integrating health topics into their programs to facilitate adult students' management of their wellbeing in the wider society (National Institutes for Literacy (NIH) 1994). As a response to these observed relations between disease or illness and low literacy, the orientation of health literacy research has been with studies establishing the relationship between literacy skills and health-related knowledge (Perrin 1989, Weiss, Hart and Pust 1991); with assessing the reading levels required to comprehend text-based health materials or assessing the readability of those materials (Davis, Crouch, Wills, Miller and Abdehou 1990, Rudd et al 1999, NIH 2000); and with attempts to measure the health literacy of populations at greater risk of ill-health due to social inequalities and experiences of social and economic hardship (Davis, 
Crouch, Wills and Miller 1991, Parker, Baker, Williams and Nurss 1995, Williams, Parker, Baker, Parikh, Coates and Nurss 1995).

More recently, understandings of health have become more nuanced, seeking to account for the many complex inter-connections between health and literacy (Nutbeam 1999, IOM 2004, Rootman and Ronson 2005). Some writers have explored the multifarious ways in which health, wellbeing and health care connect with diverse aspects of language and communication practices (Freebody and Freiberg 1999).

Following the traditional orientation of health promotion, perhaps still the dominant mode in which health literacy operates, the identified subgroup then becomes subjected to a process of individuation. It invariably becomes the object of information and attempts to elevate capability for selfmanagement (Friedsam and Kindig 2004, Cuban 2006), of alternate modes of communication such as the use of pictorial information (Houtts, Bachrach, Witmer, Tringali, Bucher and Localio 1998, Houtts, Witmer, Egeth, Loscalzo and Zabora 2001), adult literacy skills development (Hohn 2004, National Centre for the Study of Adult Learning and Literacy (NCSALL) 2005) or health literacy skills-based interventions either before or after disease has developed (National Institute for Health 2000, Schillinger, Grumbach, Piet, Wang, Osmond, Daher, Palacios, Sullivan and Bindman 2002). By implication, such strategies attribute the responsibility for developing health-related literacy skills to the sub-group. In more extreme cases the 'risky behaviour' of the target population is identified with a wider social risk and social demarcation in which 'blame', risk and protection for the wider population are invoked. Understood in this way, health literacy, as a component of health promotion, becomes an extension of citizenship duties.

Improving health professional communication skills has also been in the purview of health literacy (Weiss 2003), a factor that is within the control of health professions, whilst effecting improvement in population literacy skills is not.

At the prevention end of the continuum of health literacy activity are some instructive innovations within adult education. In adult education programs where locally meaningful social and cultural practices are incorporated into teaching and learning, inspired by Freirean principles of 'conscientisation' (Freire 1985), health promotion and health information are integrated into the lived practices of everyday routines in adults' lives. These initiatives appear to provide a psychologically safe environment for learning for adults with little or no experience of concepts such as early detection, disease prevention or regular monitoring by using diverse health topics as a catalyst for literacy instruction in speaking and listening, reading, writing, maths and critical thinking (Rudd and Comings 1994, Hohn 1998, Hohn 2004). 
Within the health literacy field there has been a similar movement to the shift within literacy discourses. There has been a move away from reductive understandings of literacy as a kind of fixed quantum of skills that determine how the targets of health promotion obtain, understand and use basic information towards a recognition of complexity. The landmark report by the US Institute of Medicine (IOM 2004) acknowledges that health literacy 'arises from a convergence of education, health services and social and cultural factors' (IOM 2004:2). This recognition of the multi-faceted relations between culture, education, social complexity and empowerment resonates strongly with the participatory empowerment philosophy of the adult literacy field (Hohn 1998, Nutbeam 1999, Shohet 2002). It also implicates a shared responsibility and significant, new opportunities for the adult education and health sectors to come together to respond to challenges in how to effectively enhance health literacy (Tassi 2004).

\section{Policy discourse of adult literacy and health fields}

Internationally, U.S. public policy, is increasingly recognising health literacy as an access and equity issue. At the federal level 'health literacy' improvements at a population level are included in its national health policy, Healthy People 2010 (US Department of Health 2001). Similarly, in the UK, national health policy discourse now explicitly stresses achievement of social justice objectives to bridge social inequalities (Department of Health 2004) and calls for much more substantial 'joined-up' thinking, referring specifically to greater integration of the efforts of various public agencies. A key illustration is the program 'Skilled for Health', a national initiative between the Department of Health and the Department for Education and Skills (Department for Education and Skills 2006), that focuses on improving literacy, language and numeracy skills of adults by embedding health improvement with adult education activities in designated socially disadvantaged areas.

In Canada, literacy and health policy connections can be traced back to 1988 , with the collaboration between the peak public health and literacy bodies and the subsequent establishment of the National Literacy and Health Program that includes a program of research, resources and plain language services (Rootman and Ronson 2005). In Europe, where health literacy is acknowledged as a 'a right of citizenship' (Kickbusch, Wait and Maag 2006:20) and considered a critical aspect of social capital, there are calls to make health literacy integral to achieving the overall goals for a healthy European citizenship (Kickbusch, Wait and Maag 2006).

The US IOM report (2004), previously cited, has been a very influential study bringing together stakeholders from different sectors and highlights explicit connections between culture, education and health literacy. The report identifies multiple stakeholders with an interest in 
pursuing the connection between literacy and health, particularly emphasising three sectors that should take on collective responsibility for health literacy and that have the capacity to build health literacy skills: culture and society, which is inclusive of broad social and cultural factors in everyday community life; the health system with its many components and settings; and the education system, including post-school, adult education programs (IOM 2004). This is a radical departure from institutional practices typified by concern for narrowly defined remits, budget management and accountability. Importantly, the IOM report, and the international initiatives cited above reflect the insight that literacy is most productively understood as a socially situated practice varying according to cultural and situational variables, behaviours and practices and issues of identity.

These international precedents raise the question of the status of health literacy in Australia. The internationally comparative statistical collections, exemplified by the International Adult Literacy Survey of 1996, undertaken by the OECD in collaboration with Statistics Canada, and involving the participation of 20 countries (Australian Bureau of Statistics 1996, OECD 1997, Wickert 2001, Hagston 2002) show considerable and persisting adult literacy difficulties among adult Australians. By some measures, some contemporary literacy requirements are challenging for almost half the population. Whilst Australia is not without innovation, health-and-literacy connections have received only marginal attention by comparison with Canada, the UK and the US. The kind of literacy policy that would include an appropriately widely-imagined health literacy suggests an imaginative agenda for communication competency which is a much more broad-ranging notion than current reductionist policy favours (Lo Bianco and Freebody 2001). Multiple literacies, and the integration of these literacies, both programmatically with non-education fields, such as health, and conceptually with each other would ideally inform an invigorated attention to the communication basis of social life in general. However, in public health there appears to be a particular mismatch between contemporary literacy skills and the demands and expectations of conventional public health operations, with pressing implications not only for health policy in general (Lonsdale and McGurry 2004) but beyond, involving questions of social capital and current social and citizenship inequalities (Hagston 2002, Hartley and Horne 2005).

Despite this generalised weakness across Australia, there have been several single, albeit ephemeral, research and practice initiatives that provide evidence of collaboration between adult literacy education and the health sector (Schwab and Sutherland 2004, Hartley and Horne 2005). State governments are beginning to invest in health literacy research to generate and use scientific knowledge to improve the health of vulnerable 
communities (Department of Human Services, 2006). We predict that each sector's interest in the other will expand, as health officials and researchers come to evaluate the effects of public health activity in ways that increasingly expose the critical mediation of language, culture and literacy, as literacy educators sharpen their awareness of the health repercussions of low literacy and as broader measures of wellbeing become accepted (Nussbaum and Sen 1993). It is a very attractive idea that professionals across both areas could productively mount a demand for a systematic policy framework in the light of the international conviction that integrated policy initiatives in health and literacy could produce strong social benefits. However, Australia is currently without any formal alliances, shared agenda, unifying framework or national approach to take forward such a metapolicy initiative, combining two already vast, but largely noncommunicating domains of public activity.

\section{Conclusions}

Education and health are key state jurisdictions with much to say to one another. Policiy in both areas is currently framed substantially within monetarist policies and neo-liberal discourses which define citizenship through the individualisation of risk and responsibility and an emphasis on individual choice (Mizen 2004, Kelly 2006). Nevertheless, we argue that despite these limitations, new approaches and practices are emerging that recognise the convergence of education and health within policy and in practice. We have drawn attention to one element in this convergence - the potential for health literacy to provide a more effective framework for the development of health promotion. The concept of health literacy involves the recognition of the diverse and complex ways in which individuals construct health and wellbeing knowledge and practices within their own context - and the extent to which this is a social practice. The recognition of the socially constructed nature of health literacy has significant implications for health promotion, pushing against the policy frameworks that seek to individualise responsibility and risk.

Driven by ever-increasing costs of health care delivery, especially the provision of hospital services, there is growing attention to emerging and chronic 'health challenges', such as population ageing, increasing prevalence of chronic diseases and the need for greater recognition of mental health issues. These are part of a public policy concern to achieve social and structural changes that will enable people to care more autonomously for their own health (Victorian Health Promotion Foundation (VHPF) 2005). There is a convergence of interest between public health, and specifically health promotion, with education processes. These interests converge particularly around the literacy capabilities of the population. This intersection of interest between health and literacy education is identified as 
a key challenge, requiring a breaking down of traditional disciplinary boundaries between the health and education institutions (VHPF 2005).

The potential for collaboration across the boundaries marked by health and education, and the permeability of these boundaries, has at times been promoted by neo-liberal ideologies of governments of the major political parties through the deployment of the notion of 'capacity building' and 'community development'. These have been the main policy strategies currently invoked for addressing the effects of poverty and inequality, and they have had the added benefit of combating the rising cost of service delivery (Botsman and Latham 2001). Inter-agency collaboration, partnership and the idea of an 'enabling state' formed the basis of the 'third way' policies of New Labour in the UK (Riddell and Tett 2001). In Australia too, state level policy frameworks, such as Creating a Fairer Victoria (Victorian Government 2006), are premised on the promise that work to increase social inclusion, foster equity and build capabilities in communities through cross-sectoral collaboration will result in social capital ties that strengthen community cohesion and lessen effects of poverty and alienation.

Working across departmental, service and sectoral boundaries presents considerable challenges, including ambiguity about responsibilities and accountabilities, different approaches to measuring outcomes, different uses of language and different approaches to problems and their solution (Wierenga, Wyn, Glover and Meade 2003:28). However, the ways in which inter-sectoral collaborations can recognise and value the significance of practitioner knowledge and provide a framework within which bureaucratic and often outmoded practices can be superseded are also in evidence (Victorian Government 2006).

Independently, within both health and adult literacy, there has been a convergence of interest and preoccupation around how personal selfmanagement, the project of autonomous personhood imagined in the neoliberal ideologies of public action today, involves competent literate behaviour in which the management of the body, and therefore of health, is a central element. Both theoretical and practical policy consequences are implicated in the independent discovery of the mutual relevance of health and literacy. A central organising principle for future elaboration of the fields will be how social and cultural identities are centrally linked to learning and health outcomes.

Our discussion highlights a perspective on social and cultural identities that recognises the embeddedness of these identities in relationships and practices that go well beyond individuals, to populations. Health literacy is constructed and enacted within communities - it is important that policies also recognise the need to look beyond the unit of the individual for health promotion, to recognising the way in which health literacy is practised in families, amongst friends and in communities of 
interest or proximity. Neo-liberal policies have tended to focus on ensuring that individuals bear responsibility for their own health. The health challenges faced today are more likely to be adequately addressed through significant policy and resource provision reflecting state and national responsibility for enhancing the social determinants of good health and wellbeing.

\section{Acknowledgement}

Julie Green is supported by the National Health and Medical Research Council (Australia) Postgraduate Scholarship (Public Health).

\section{References}

Australian Bureau of Statistics (ABS) (1996) Aspects of Literacy, Australia Cat no. 4228.0, Australian Bureau of Statistics, Canberra.

Australian Institute of Health and Welfare (AIHW) (2004) Health Inequalities in Australia: Mortality, September 2004, Health Inequalities Monitoring Series no 1, Catalogue Number PHE 55 QUT and AIHW, Canberra.

Baker DW, Parker RM, Williams MV, Pitkin, K, Parikh, NS, Coates, W and Imara, M (1996) The Health Care Experience of Patients with Low Literacy, Archives of Family Medicine, vol 5, pp 329-34.

Baker, DW, Parker, RM, Williams, MV and Clark, WS (1998) Health Literacy and the Risk of Hospital Admission, Fournal General Internal Medicine, December, vol 13, no 12, pp 791-8.

Barton, David and Hamilton, Mary (1998) Local Literacies: Reading and writing in one community, Routledge, London.

Barton, David, Hamilton, Mary and Ivanič, Ros (2000) Situated Literacies: reading and writing in context, Routledge, London.

Baynham, Michael (1995) Literacy Practices: Investigating literacy in social contexts, Routledge, London.

Baynham, Michael (2003), Adult Literacy, in Bourne, J and Reid, E, eds, Language Education, World Yearbook, 2003 Kogan Page, London, pp 109-126.

Beck, U and Beck-Gernsheim, E (2002) Individualization, Sage, Thousand Oaks, California.

Botsman, Peter and Latham, Mark (2001) The Enabling State, Pluto Press, Annandale, New South Wales.

Gentre for Literacy (CLQ (2000)A Working Definition: Literacy for the 21st century, retrieved on 13 December 2006 from www.centreforliteracy.qc.ca/def.htm, The Centre for Literacy of Quebec, Montreal, Canada. 
Collins, J (1999) The Ebonics Controversy in Context, in Blommaert, J, ed, Language Ideological Debates, The Hague, Mouton, pp 201-235.

Cope, Brian and Kalantzis, Mary (2000) Multiliteracies, Routledge, London. Cuban, S (2006) Following the Physician's Recommendations Faithfully and Accurately, Fournal for Critical Education Policy Studies, vol 4, no 2, November, retrieved on 1 August 2007 from www.jceps.com/?pageID=article\&articleID $=74$.

Davis, T, Grouch, M, Wills, G, Miller, S, and Abdehou, D (1990) Gap Between Patient Reading Comprehension and the Readability of Patient Education Materials, Fournal of Family Practice, vol 31, no 5, pp 533-538.

Davis, T, Crouch, M, Wills, G, and Miller, S (1991) Rapid Assessment of Literacy Levels of Adult Primary Care Patients, Family Medicine, vol 23, no 6, pp 433-435.

Department for Education and Skills (2006) Skilled for Health: Making the case, London (unpublished).

Department of Health (2004) Choosing Health: Making healthy choices easier, Public Health White Paper, England, November.

Department of Human Services, (2006) Health Literacy and Effective Health Promotion for Vulnerable Communities, retrieved on $21^{\text {st }}$ November 2006 from http://health.vic.gov.au/researchprograms/ Vic, Australia.

Dreger V and Tremback T (2002) Optimize Patient Health by Treating Literacy and Language Barriers, Association of Perioperative Registered Nurses, February, vol 75, no 2, pp 278-304.

Freebody, Peter and Freiberg, Jill (1997) Adult Literacy and Health, Language Australia, Melbourne.

Friedsam, D and Kindig, D (2004) Consumer Health Literacy, Wisconsin Public Health and Health Policy Institute Issue Brief, vol 5, no 4, May, http://pophealth.wisc.edu/uwphi/publications/birefs/may04brief.pdf.

Friere, $\mathrm{P}$ (1985) The Politics of Education, MacMillan, London.

Gazmararian, JA, Baker, DW, Williams, MV, Parker, RM, Scott, TL, Green, DC, Fehrenback, SN, Ren, J, Koplan, JP (1999) Health Literacy among Medicare Enrolees in a Managed Care Organisation, Journal of American Medical Association, February, vol 10, no 281, pp $545-51$.

Hagston, Jan (2002) Exploring the International Adult Literacy Survey Data, Language Australia, Melbourne.

Hamilton, Mary (2001) Privileged Literacies, Language and Education, vol 15, nos 2 and 3, pp 178-196.

Hartley, Robyn and Horne, Jackie (2005) Social and Economic Benefits of Improved Adult Literacy, National Centre for Vocational Education Research, Adelaide, http://ncver.edu.au. 
Heath, Shirley (1983), Ways With Words, Cambridge University Press, London.

Hohn Marcia, D (1998) Empowerment Health Education in Adult Literacy, National Institute for Literacy Washington, DC, retrieved on 5 August 2006 from www.nifl.gov/HOHN.htm.

Hohn Marcia, D (2004) A Peer Leadership and Empowerment Approach to Health Literacy Education, Literacy Harvest, Fall 2004, vol 2, no 1, Health Literacy, pp 12-18.

Houtts, PS, Bachrach, R, Witmer, JT, Tringali, CA, Bucher, JA, Localio, RA (1998) Using Pictographs to Enhance Recall of Spoken Medical Instructions, Patient Education and Counseling, vol 35, pp 83-88.

Houtts, PS, Witmer, JT, Egeth, HE, Loscalzo, MJ and Zabora, JR (2001) Using Pictorgraphs to Enhance Recall of Spoken Medical Instructions II, Patient Education and Counseling, vol 43, pp 231-242.

Institute of Medicine (IOM) (2004) Health Literacy, in Nielsen-Bohlman, L, Panzer, AM, Kindig, DA, eds, Institute of Medicine of the National Academies.

Kalman, J (1999) Writing on the Plaza, Hampton Press, Cresskill NJ.

Kelly, P (2006) The Entrepreneurial Self and 'Youth at-risk', Fournal of Youth Studies, vol 9, no 1, pp 17-32.

Kickbusch, I (2001) Health Literacy, Health Promotion International, vol 16, no 3, pp 289-297.

Kickbusch, Illona, Wait, Suzanne and Maag, Daniela, (2006) Navigating Health, International Longevity Centre, London, England.

Lindau, ST, Tomori, C, Lyons, T, Langseth L, Bennett, CL, Garcia, P (2002) The Association of Health Literacy with Cervical Cancer, American Fournal of Obstetrics and Gynecology, vol 186, no 5, pp 938-43.

Lo Bianco, Joseph and Freebody, Peter (2001) Australian Literacies, Language Australia, Melbourne.

Lonsdale, M and McCurry, D (2004) Literacy in the New Millennium, National Centre for Vocational Education Research, Publication 1490, www.ncver.edu.au/publications/1490.html.

Marmot, Michael (2004) Interview with Professor Michael Marmot, World Health Organisation, retrieved on 13 December 2006 from www.who.int/social_determinants/advocacy/interview_marmot/en/

Mizen, P (2004) The Changing State of Youth, Palgrave, New York.

National Centre for the Study of Adult Learning and Literacy (NCSALL) (2005) Learning How to Teach Health Literacy, vol 8, issue 3, retrieved on 13 December 2006 from ww.ncsall.net/?id=995.

National Institute for Literacy (1994) Literacy for Health, February 7, ERIC Document Reproduction Service, Springfield VA. ED404436.

National Institute of Health (2000) Current Bibliographies in Medicine, January 1990-October 1999, US Department of Health and Human Services, Bethesda, Maryland, No 2000-1. 
Nussbaum, M and Sen, A (1993) The Quality of Life, Clarendon Press, Oxford.

Nutbeam, Don (1999) Literacies Across the Lifespan, Literacy and Numeracy Studies: An international journal in the education and training of adults, vol 9, no 2, pp 47-55.

Nutbeam, Don (2000) Health Literacy as a Public Health Goal, Health Promotion International, vol 15, no 3, September, pp 259-267.

Nutbeam, Don (2005) What Would the Ottawa Charter Look Like if It Were Written today?, International Union for Health Promotion and Education (IUHPE), retrieved on 20th November from www.rj[eo.org/reviews/2005/19/index.htm.

Nutbeam, D and Harris, E (1998) Theory in a Nutshell, Department of Public Health and Community Medicine, University of Sydney, NSW.

Nutbeam, Don and Kickbusch, Ilona (2000) Advancing Health Literacy, Health Promotion International, September 1, vol 15, no 3, pp 183-4.

Organisation for Economic Cooperation and Development, OECD (1996) Lifelong Learning for All, Organisation for Economic Cooperation and Development (OECD), Paris.

Organisation for Economic Cooperation and Development, OECD (1997) Literacy Skill for the Knoweledge Society, Organisation for Economic Cooperation and Development (OECD), Paris.

Pamuk, E, Makuc, D, Heck, K, Reuben, C, and Lochner, K (1998) Socioeconomic Status and Health Chartbook, US, 1998, National Center for Health Statistics, Hyattsville, MD.

Parker, R, Baker, D, Williams, M, and Nurss, J (1995) The Test of Functional Health Literacy in Adults, Fournal of General Internal Medicine, vol 10, pp 537-41.

Parsons, S and Bynner, J (1998) Influences on Adult Basic Skills, Basic Skills Agency, London.

Perrin, B (1989) Literacy and Health: Making the connection, Health Promotion, vol 28, no 1, pp 2-5.

Prinsloo, M and Breier, M (1996) The Social Uses of Literacy, Benjamins, Amsterdam.

Ratzan SC and Parker RM (2000) Introduction, in Selden, CR, Zorn, M, Ratzan, SC, Parker, RM, eds, in National Library of Medicine Current Bibliographies in Medicine: Health Literacy, vol NLM Publication no CBM 2000-1, National Institutes of Health, US Department of Health and Human Services, Bethesda.

Riddell, S and Tett, L, eds (2001) Education, Social fustice and Inter-agency working, Routledge/Farmer, London.

Rootman, I and Ronson, B, (2005) Literacy and Health Research in Canada, Canadian Fournal of Public Health, S63, March-April, pp 62-77.

Rudd, RE and Comings, JP (1994) Learner Developed Materials, Health Education Quarterly, Fall, vol 21, no 3, pp 313-327. 
Rudd, Rima, Moeykens, Barbara and Colton, Taylor (1999) Health and Literacy, in Comings, J, Garners, B, Smith, G, eds, Annual Review of Adult Learning and Literacy, Josey-Bass, San Francisco.

Rudd, Rima, Kirsch, Irwin and Yamamoto K, (2004) Literacy and Health in America, ETS, retrieved on 10 November 2006 from www.ets.org/research/pic

Schillinger, D, Grumbach, K, Piett, J, Wang, F, Osmond, D, Daher C, Palacios, J, Sullivan, GD, Bindman, AB (2002) Association of Health Literacy with Diabetes Outcomes, Fournal of American Medical Association, vol 288, pp 475-482.

Schwab, RG and Sutherland, D (2004) Literacy for Life, Centre for Aboriginal Economic Policy Research (CAEPR), Australian National University, Australia, retrieved on 13 December 2006 from www.anu.edu.au/caepr/Publications/topical/LiteracyforLife.pdf

Shohet, Linda (2002) Health and Literacy: Perspectives, retrieved on 6 June 2006 from www.staff.vu.edu.au/alnarc/onlineforum/AL_pap_shohet.htm

Silverstein, M, Iverson, L and Lozano, P (2002) An English-Language Clinic-based Literacy Program is Effective for a Multilingual Population, Pediatrics, vol 109, no 5, e76.

Snyder, I, Jones, A and Lo Bianco, J (2005) Using Information and Communication Technologies in Adult Literacy Education, National Centre for Vocational Education Research (NCVER), ncver.edu.au

Street, Brian (1995) Social Literacies, Longman, London.

Street, Brian, ed, (2001) Literacy and Development, Routledge, London.

Street, Brian (2003) What's 'New' in New Literacy Studies?, Current Issues in Comparative Education, vol 5 no 2, pp 1-19.

Tassi, A (2004) The Emergence of Health Literacy as a Public Policy Priority, Literacy Harvest, Health Literacy, Fall, vol 2, no 1, pp 5-10.

Turrell, G, Stanley, L, de Looper M, and Oldenburg, B, (2006) Health Inequalities Monitoring Series No 2, AIHW April, AIHW Cat. No. PHE 72.

United Nations Eductional, Scientific and Cultural Organisation (UNESCO) (2005) Education For All Global Monitoring Report, http://portal.unesco.org/education/en/ev.php-

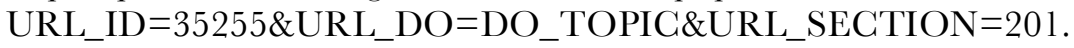
html

US Department of Health and Human Services (2001) Healthy People 2010, http://www.health.gov/healthypeople.

Victorian Government (2006) Creating A Fairer Victoria, retrieved on 9 December 2006 from www.vic.gov.au

Victorian Health Promotion Foundation (VHPF) (2005) Plan for Action 20052007, Victorian Health Promotion Foundation, retrieved on 12 March 2006 from www.vichealth.vic.health.gov.au

Weiss, Barry (2003) Health Literacy, American Medical Association. 
Weiss, B, Hart, G, and Pust, R (1991) The Relationship Between Literacy and Health, Fournal of Health Care for the Poor and Underserved, vol 1, no 4, pp 351-363.

Wickert, Rosie (2001) Politics, Activism ... Policy Production: Adult literacy in Australia, in Lo Bianco, J and Wickert, R, eds, Australian Policy Activism, Language Australia, Melbourne, pp 75-93.

Wierenga, A, Wyn, J, Glover, S and Meade, M (2003) Application of Enabling State Principles in the Delivery of Youth Services, Youth Research Centre, Melbourne.

Williams, M, Parker, R, Baker, D, Parikh, K, Coates, W and Nurss, J (1995) Inadequate Functional Health Literacy Among Patients at Two Public Health Hospitals, Fournal of the American Medical Association, vol 2714, no 21, pp 1677-1682.

Williams MV, Baker DW, Honig EG, Lee, ML and Nowlan, A (1998) Inadequate Literacy is a Barrier to Asthma Knowledge and Self-care. Chest, vol 114, pp 1008-15.

World Health Organisation (WHO) (1986), 21 November, retrieved on 4 October 2006 from www.who.int/hpr/NPH/docs/ottawa_charter_hp.pdf

World Health Organisation (WHO) (1998) World Health Declaration, May, www.who.int 
